\title{
Prevalence of Intestinal Parasitic Infection in children among age of 6 to 12 years in rural area of Bareilly District: Cross Sectional Study
}

Ashish Kr Sharma ${ }^{1}$, Swati Khan ${ }^{2}$

${ }^{1}$ Assistant Professor, Department of Community Medicine, Autonomous State Medical College and Society, Firozabad, Uttar Pradesh; ${ }^{2}$ Professor, Department of Community Medicine, Rohilkhand Medical College and Hospital, Bareilly, Uttar Pradesh

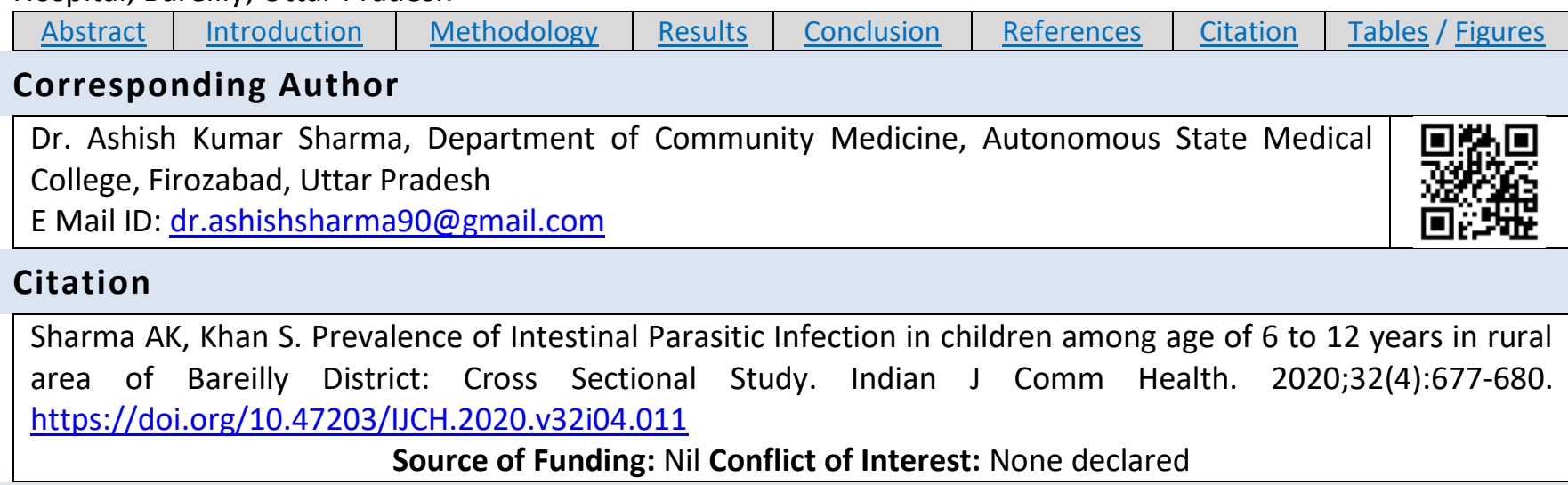

Article Cycle

Received: 30/09/2020; Revision: 11/11/2020; Accepted: 05/12/2020; Published: 31/12/2020

This work is licensed under a Creative Commons Attribution 4.0 International License.

\section{Abstract}

Background: In India overall prevalence rate of intestinal parasitic infection ranges from $12.5 \%$ to $66 \%$ with varying prevalence rate for individual parasite. About $50 \%$ of the urban population and $68 \%$ of the rural population in India is affected. Aim: Prevalence of Intestinal Parasitic Infection in children among age of 6 to 12 years in rural area of Bareilly District Material and Methods: A cross sectional study was conducted using multistage random sampling technique in rural area of Bareilly District, Uttar Pradesh, India, from November 2016 - October 2017. Result: Among 248 children, the prevalence of intestinal parasitic infestation in 6-12 years of aged children was found to be $33.90 \%$. Conclusion: This study revealed high prevalence of intestinal parasitic infection among 6-12 years of age children in Rural Area of Bareilly District.

\section{Keywords}

Intestinal Parasitic Infection; Bareilly; Prevalence Rate

\section{Introduction}

Early childhood development is considered to be the most important phase in life which determines the quality of health, well-being, learning and behaviour across the life span. It is a period of great opportunity, but also of great vulnerability to negative influences and constitutes a unique phase for capitalizing on developmental forces to prevent or minimize disabilities and potential secondary conditions. The course that development takes in each person depends critically on the quality of stimulation, support and nurturance that the child experiences in his or her family, neighbourhood, and care environments. When these are deficient or

unsupportive child development can be seriously malaffected.(1)

In India prevalence of intestinal parasites reported from different workers showed wide variation in incidence due to different time, place and method used. The frequency and incidence of Intestinal parasites also varies with age, sex and geography. Amoebiasis, Giardiasis, Ascariasis, Hookworm infection, and Trichuriasis are among the most common intestinal parasitic infection worldwide.(2) In India overall prevalence rate of intestinal parasitic infection ranges from $12.5 \%$ to $66 \%$ with varying prevalence rate for individual parasite. About $50 \%$ of the urban population and $68 \%$ of the rural 

population in India is affected. The global burden by Disability-adjusted-life-year (DALY) of soil transmitted helminthic diseases is comparable to tuberculosis and Malaria. $(3,4,5,6,7)$

The present study entitled Prevalence of Intestinal Parasitic Infection in children among age of 6 to 12 years in rural area of Bareilly District: Cross Sectional Study to evaluate the prevalence rate of Intestinal parasitic Infestation in 6 - 12 years of age children.

\section{Aims \& Objectives}

The aim of the study is Prevalence of Intestinal Parasitic Infection in children among age of 6 to 12 years in rural area of Bareilly District and the objective of the study were to estimate the prevalence rate in children.

\section{Material \& Methods}

The study was conducted in Children of 6-12 years of age in rural area of Bareilly District between November 2016 to October 2017. The type of study was Cross sectional observational community-based study. The study participants included in the study who was between 6-12 years of age, also those study participants, whose Parents gave consent to allow their children to participant in the study, those study participants who was residing in the study area since past 6 month and those study participants who were not on any therapy e.g. antibiotic/any other drugs due to any disease during survey. In this study those participants were excluded who were not fulfilling any inclusion criteria. The sample size was estimated on the basis of prevalence. Initially we calculated the sample size on the basis of Prevalence of Parasitic Infestation (37.6\%). (8) $P=37 \%, Q=100-P=63, L$ (Allowable error) $=15 \%$ of $P$ (Relative Error) $=15 \%$ of 37 , so sample size calculate by $4 \mathrm{PQ} / \mathrm{L} 2$, sample size was 308 . We took $10 \%$ of that sample size for pilot study i.e. $30.8=30$. On the basis of pilot study, we calculate prevalence which comes $44 \%$. On the basis of this prevalence, we calculated sample size. $\mathrm{P}=$ $44 \%, Q=100-P=56 \mathrm{~L}$ (Allowable error) $=15 \%$ of $P$ (Relative Error) $=15 \%$ of 44 , so final sample size calculated by $4 \mathrm{PO} / \mathrm{L} 2$, sample size was 226 . On taking $10 \%$ non-response rate of total sample size $=22$ so final sample size was rounded up to 248 (approximate). The Multi-Stage Sampling Technique was used for the study. We used open ended questionnaire to obtain Name, Age, Sex and Address with fulfilling the inclusion criteria. Permission had taken from ethical committee. To participate the study participants permission had also from the parents in an informed consent. To estimate the prevalence Stool sample were taken for macroscopic examination and microscopic examination and all enrolled children provided a container to collect the stool. Precautions had taken without diluting it with urine or water. The Specimen collected next morning from houses in the morning and transferred to the Laboratory for examination. The specimens adequately identified by labels indicating code number, name, age and sex. If a child's parents were not willing to give stool sample after giving informed consent in next morning then we counselled the parents and followed them for 3 consecutive days. If Still, They, were not willing to participate, we excluded from study as per Exclude Criteria of Study and then went to the Pradhan and Health Worker of each selected village and collected the data of 6-12 years aged children with explaining them the purpose of study. Data was entered in Microsoft Excel by the principal author and analysed by IBM SPSS (Statistical Package for Social Science) v 23 for interpretation and conclusion from data.

\section{Results}

A total of 248 children of $6-12$ years of age of rural area were interviewed and inspected with stool routine microscopic examination. Considering this view, Prevalence was estimated for intestinal parasitic infestation.

Fig. shows that among 248 children, 33.9\% (84) cases were found positive after stool routine microscopic examination while $66.1 \%$ (164) cases were found negative after stool routine microscopic examination so, prevalence of intestinal parasitic infestation is 33.9\%. (Figure 1)

\section{Discussion}

Intestinal parasitic infections are endemic worldwide and remain a major public health concern in many tropical and subtropical countries. The prevalence rates of intestinal parasitic infections and type of parasite exhibit wide variation from country to country, between geographical areas, communities, and even seasons. (9) Infestation by soil-transmitted Helminths is a serious public health problem in developing countries like India. It is a major cause of morbidity in school-age children, who have the highest burden of worm infestation. Some of the morbid conditions attributed to intestinal helminthiasis are malnutrition, growth retardation, anaemia, vitamin A deficiency, and impaired intellectual performance. Impairment of physical 
and mental development has also been identified as a deleterious effect of helminthic infection. As a result, there have been concerted efforts to control this group of diseases, especially among children who are the most vulnerable. However, knowing the prevalence of multiple infections will strengthen, or otherwise justify, the use of broad-spectrum anti helminthic in the prophylaxis and treatment of intestinal Helminths in children.(10) In the present study, the overall prevalence of intestinal parasitic infestation is $33.9 \%$ after screening the study participants (84/248) but on a other hand, in another study conducted in North Maharashtra by Manisha Mane et al (2014)(11) the overall prevalence of intestinal parasitic infestation was estimated to be $37.66 \%$ which is nearly similar to our study and in another study conducted in Gujarat by Hitesh Assudani et al (2015)(12) the overall prevalence of intestinal parasitic infestation was estimated to be $13.33 \%$. Various studies have shown that prevalence rate in India ranges from $12.5 \%$ to $66 \%$ with varying prevalence for individual parasites. $(13,14,15,16,17)$ The wide variation in the prevalence of intestinal parasites may be due to variations in factors like quality of drinking water supply, sanitation and other environmental conditions and also lack of knowledge, personal hygiene.

\section{Conclusion}

The present study was conducted in Rural area of Bareilly District in between November 2016 to October 2017 in 248 Children aged between 6 to 12 years old. The study was carried out with an aim to study the prevalence of intestinal parasitic infestation of 6 to 12 years of age group in rural area of Bareilly District. So, in this study, it was found that 33.9\% of study participants were found positive for Intestinal Parasitic Infestation.

\section{Recommendation}

After conducting the study, the major recommendation of the study are: The improvement of general standard of sanitation through the mandatory installation of the suitable sewage treatment, disposal facilities and provision of pipeborne water supply for successful prevention and control. For controlling of these parasitic infestations, there is need for periodic deworming, regular epidemiological surveillance and raising awareness about personal hygiene, Early diagnosis by parasitological examination and complete treatment of those infected are important for controlling measures.

\section{Relevance of the study}

Present study is focused on child aged between 6 to 12 years of rural area because children of rural area are more prone to Intestinal Parasitic Infestation due to unawareness of personal hygiene, improper sanitation like sewage system, disposal facilities and water supply.

\section{Authors Contribution}

Both authors has contributed in the study equally in Design, Data analysis, and interpretation of data.

\section{Acknowledgement}

Authors duly acknowledge the participants and their parents for their support provided in completing the study.

\section{References}

1. World Health Organization. Early child development Available from www.who.int/maternal child adolescent/topics/child/development/en/\# [Last accessed on 2020 Dec 20]

2. Choubisa SL, Jaroli VJ, Choubisa P, Mogra N. Intestinal parasitic infection in Bhil tribe of Rajasthan, India. J Parasit Dis. 2012;36(2):143-8. doi: 10.1007/s12639-012-0151-y. Epub 2012 Aug 2. PMID: 24082517; PMCID: PMC3427671.[PubMed]

3. Dr. Champa S, Mrs. Sreeshma $P$ Intestinal Parasitic Infestation among Patients attending a tertiary care hospital in South India Journal of Evolution of Medical and Dental Sciences 2012; 1(4): 308-314

4. Naish S, McCarthy J, Williams GM. Prevalence, intensity and risk factors for soil-transmitted helminth infection in a South Indian fishing village. Acta Trop. 2004;91(2):177-87. doi: 10.1016/j.actatropica.2004.04.004. PMID 15234667.[PubMed]

5. Srihari N, Kumudini TS, Mariraj J, Krishna S. The prevalence of intestinal parasitic infections in a teritiary care hospitala retrospective study. J Pharm Biomed Sci. 2011:1-4.

6. Jardim-Botelho A, Raff $S$, Rodrigues Rde A, Hoffman $\mathrm{HJ}$, Diemert DJ, Corrêa- Oliveira R, Bethony JM, Gazzinelli MF. Hookworm, Ascaris lumbricoides infection and polyparasitism associated with poor cognitive performance in Brazilian schoolchildren. Trop Med Int Health. 2008;13(8):994-1004. doi: 10.1111/j.13653156.2008.02103.x. Epub 2008 Jul 9. PMID: 18627581.[PubMed].

7. Bethony J, Brooker S, Albonico M,et al. Soil transmitted helminth infections: Ascariasis,trichuriasis, hookworm. Lancet 2006; 152-3.

8. Sucheta. J. Lakhani, Mrs. Radhika Rana Khara, Dr. Sunanda Joshi, Dr. Smriti Vasisht. Intestinal Parasitic Infections among school children in PipariaVillage, Vadodara District, International Journal of Scientific Research, 2013,2(12).

9. World Health Organization. Control of Tropical Diseases. Geneva, Switzerland: WHO; 1998. 
10. Sah RB, Paudel IS, Baral R, Poudel P, Jha N, Pokharel PK Prevalence of Intestinal Helminthic infections and associated risk factors. Indian Journal of Community Health, 2013;25(2).

11. Salam N, Azam S. Prevalence and distribution of soiltransmitted helminth infections in India. BMC Public Health. 2017; 16;17(1):201. doi: 10.1186/s12889-017-4113-2. PMID: 28209148; PMCID: PMC5311856.[PubMed]

12. Problem Distribution of India: www.who.int/neglecteddisease/preventive chemothrapy/sth/db/?units=minimal\&region=all\&country =all\&countries=all\&year=all [Last accessed on 2020 Dec 20]

13. Rationale of Study. Available from www.nhm.gov.in/national-deworming-day.html [Last accessed on 2020 Dec 20]
14. Atul Aher, Sanjeev Kulkarni. Prevalence of Intestinal Parasites in School Going Children in a Rural Community International Journal of Biomedical Research, IJBR,2011;2:605-607

15. Waseem Anjum, Pavan S. Kalasker, Kurre Bhaskar Prevalence of intestinal parasites and its associated sociodemographic factors among the food handlers of Bagalkot city, Karnataka, India, International Journal of Community Medicine and Public Health. 2017;4(1).

16. Tripathi Kiran, Nema Shashwati, Bankwar Vishal, Dhanvijay Ashok kumar Intestinal Parasitic infections and Demographic status of school children in Bhopal region of Central India. Journal of Pharmacy and Biological Sciences. 2014; 9(5) II: 83-87

\section{Figures}

\section{FIGURE 1 PREVALENCE OF INTESTINAL PARASITIC INFESTATION (N=248)}

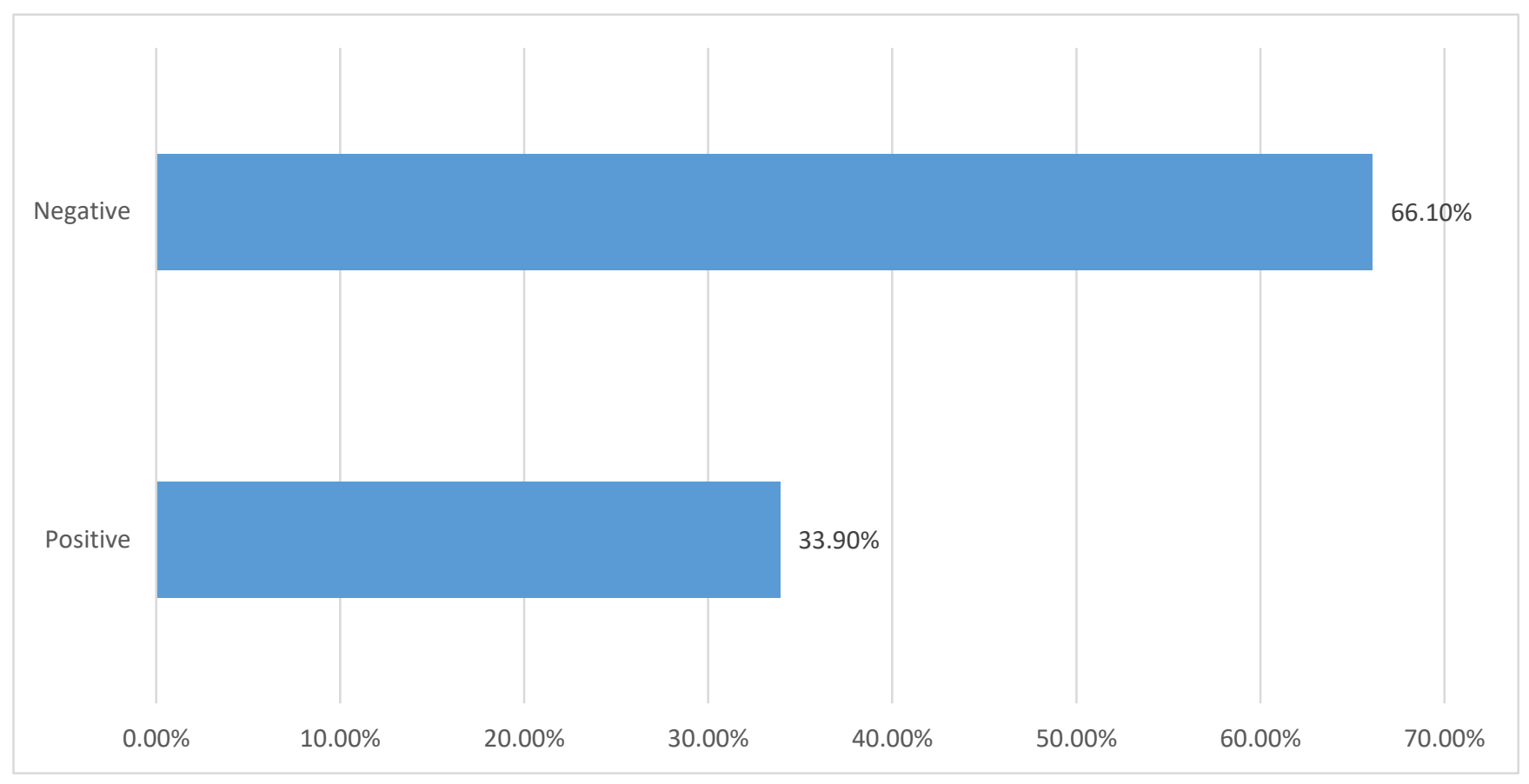

